\title{
The efficacy of Hemospray in patients with upper gastrointestinal bleeding from tumor
}

Authors

Institution
Rapat Pittayanon, Piyapan Prueksapanich, Rungsun Rerknimitr

Division of Gastroenterology, Department of Medicine, Chulalongkorn University and King Chulalongkorn Memorial Hospital The Thai Red Cross, Bangkok, Thailand submitted 5. February 2016 accepted after revision 10. May 2016

\section{Bibliography}

Dol http://dx.doi.org/ 10.1055/s-0042-109863 Published online: 31.8.2016 Endoscopy International Open 2016; 04: E933-E936

(c) Georg Thieme Verlag KG Stuttgart . New York E-ISSN 2196-9736

\section{Corresponding author}

\section{Rungsun Rerknimitr, MD}

Professor of Medicine

Division of Gastroenterology

Department of Medicine

Faculty of Medicine

Chulalongkorn University

Bangkok 10330

Thailand

Phone: 66-2-256-4265

Fax: 66-2-252-7839

ERCP@live.com
Background and study aims: Currently, conventional endoscopic treatments provide an unsatisfactory hemostatic outcome in upper gastrointestinal bleeding from tumor. Hemospray has been shown to be useful in many active gastrointestinal bleeding conditions. This study aimed to compare the efficacy of Hemospray and conventional endoscopic hemostasis.

Patients and methods: Fourteen patients with active upper gastrointestinal bleeding from tumor were recruited. Hemospray was applied at the bleeding site until hemostasis was achieved. Four patients were excluded because they prematurely received definitive therapy to prevent further bleeding within 48 hours. Another 10 patients from historical control were matched based on the type of gastrointestinal tumors. The 14-day rebleeding rates, length of hospital stay (LOS) and mortality rate at 30-day follow up were assessed.

\section{Introduction}

$\nabla$

Tumor-related gastrointestinal bleeding is currently a challenging clinical problem [1]. A retrospective review of upper gastrointestinal bleeding in 55 patients with primary or metastatic gastrointestinal malignancy revealed that up to $20 \%$ were related to tumor invading gastrointestinal lumen and causing bleeding [2]. Currently, endoscopy is recommended as the main diagnostic tool to locate the site of bleeding $[2,3]$. Unfortunately, current endoscopic hemostatic methods including coaptation therapy, argon plasma coagulation, and mechanical hemostasis do not reliably control active bleeding, with rates of successful immediate hemostasis as low as $40 \%$ and a significant short-term rebleeding rate (up to $30 \%$ ) $[1,4$, 5]. Surgery, embolization, and radiotherapy can serve as salvage hemostasis because they are more effective $(50 \%-100 \%)$ with lower rates of rebleeding $(0-18 \%)$ [6-8]. However, a bridging
Results: Baseline characteristics including age, stage of tumor, and Blatchford score did not differ between the two groups. The 14-day rebleeding rate in the Hemospray group was 3 times lower than the control group but not statistically significant ( $10 \%$ vs. $30 \%$; $P=0.60)$. LOS was no different between the 2 groups $(28.2 \pm 21.2$ vs. $23.8 \pm 12.5$ days; $P=0.26$ ). The 30 -day mortality rate in the Hemospray group was 3 times lower than that of in the conventional therapy group but not significant ( $10 \%$ vs. $30 \%, P=0.7$ ).

Conclusions: Hemospray is a promising therapy for initial hemostasis in upper gastrointestinal bleeding from tumor because it can achieve hemostasis during the first 14 days, thus potentially allowing sufficient time before appropriate definitive intervention is considered.

endoscopic therapy is required during resuscitation and stabilization of patients.

Hemospray is an inorganic powder not absorbed or metabolized by mucosal tissue. When in contact with blood, its adhesive properties result in a physical barrier that covers the bleeding site. The Hemospray barrier is stable because of the effect of accumulation of clotting factors, and consequently the bleeding point is not exposed to acid, allowing the healing process to continue [9]. Neither luminal nor systemic side effects have been reported with the product [9-11].

Recently, Hemospray has been proposed as a novel way of producing endoscopic hemostasis for active gastrointestinal (gastrointestinal) bleeding, mostly for ulcer bleeding [9]. To date, the study of Hemospray in tumor bleeding is limited as results have not focused on this particular patient group [9-15]. This study aimed to compare the hemostatic efficacy of Hemospray with that of conven- 

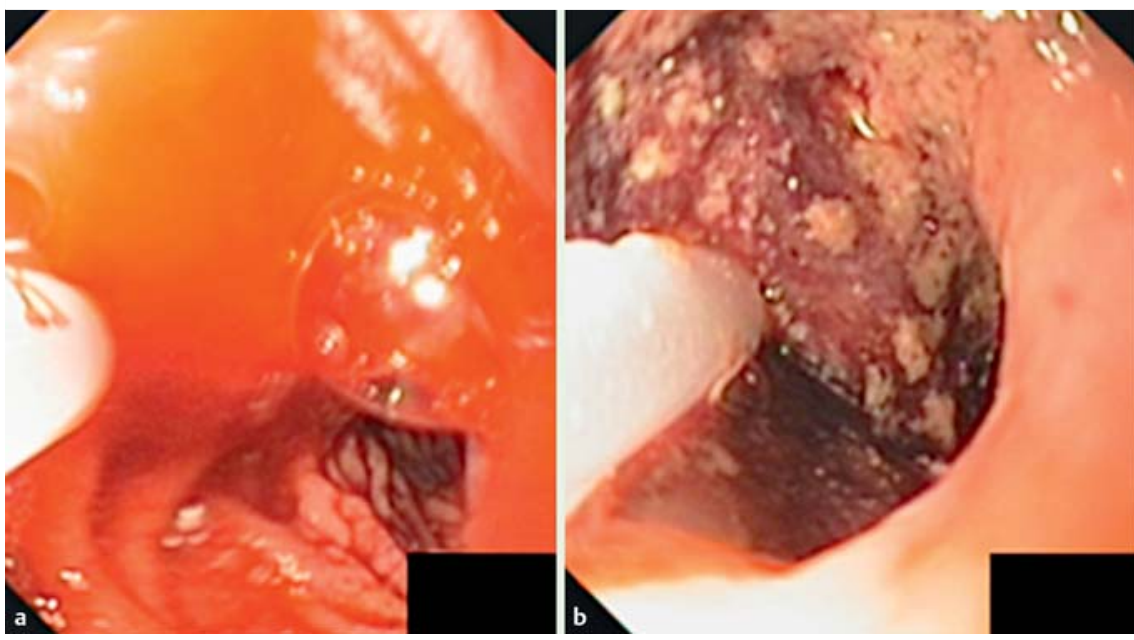

Fig. 1 Pictures of active tumor bleeding (a) and post Hemospray (b).

tional endoscopic treatment in patients who presented with upper gastrointestinal bleeding from tumor.

\section{Patients and methods \\ $\nabla$}

\section{Patients}

Between January 2014 and January 2015, patients with a history of upper gastrointestinal bleeding from primary gastrointestinal malignancy or metastasis who presented at the King Chulalongkorn Memorial Hospital were enrolled. The inclusion criteria were as follows: 1 ) male or female patient, 18 years of age or older; 2) ability to provide written informed consent; and 3) presence of active bleeding from tumor during endoscopy. Patients were excluded if they had received any definitive treatment, such as surgery, embolization or radiation within the first 48 hours (unable to evaluate the hemostatic result of Hemospray). For the control group, the authors retrieved matched cases from the hospital electronic database during the previous 5 years using the key words "upper gastrointestinal bleeding AND cancer". Tumor location was used as the criterion for matching and the patients were further divided into those with upper gastrointestinal tumor and those with hepatico-pancreaticobiliary tumor corresponding to the Hemospray group.

In both groups, patient gender, age, type and stage of malignancy, Blatchford score, amount of blood transfusions, number of endoscopies needed, and requirement for additional interventions including endoscopy, surgery, adjuvant embolization, and radiotherapy during admission were analyzed. The 14-day rebleeding rates, lengths of hospital stay (LOS), and mortality rate at 30-day follow up were assessed. The study protocol and consent form were approved by the Chulalongkorn University Institutional Review Board (No.092/58).

\section{Instruments}

Hemospray or TC-325 (Cook Medical, Winston-Salem, North Carolina, USA) was used as the only hemostatic method with the maximum dose of $20 \mathrm{~g}$ ( 1 cartridge).

\section{Endoscopic procedure}

Medical resuscitation described elsewhere for upper gastrointestinal bleeding [16] was initiated in all eligible patients. Following medical resuscitation, therapeutic esophagogastroduodenoscopy (EGD) was performed by an experienced endoscopist (RP) certified in Hemospray endoscopic hemostasis. If tumor bleeding was identified, Hemospray tube was applied through a 10-Fr catheter in which the powder was sprayed onto the bleeding site until hemostasis was achieved, but no more than 1 cartridge was used. Successful initial hemostasis was defined as no further active bleeding seen at least 5 minutes before withdrawing an endoscope after Hemospray was applied ( $\bullet$ Fig. $\mathbf{1})$.

Then standard post-endoscopic care with a 72-hr proton pump inhibitor infusion was prescribed in all patients [16]. Re-EGD was done in patients with suspected rebleeding, which was defined as: 1) $3 \%$ of more drop in hematocrit level even after adequate blood transfusion; and 2) new development of hematemesis or hematochezia or melena.

\section{Statistical analysis}

For numerical variables, the results were expressed as a mean \pm $\mathrm{SD}$, whereas other quantitative variables are expressed as percentages. Continuous variables were compared by the student's $\mathrm{t}$ test. Discontinuous variables were compared by the chi-square (x2) test. SPSS version 17.0 (SPSS (Thailand) Co., Ltd., Bangkok, Thailand) for Windows systems was used for statistical analysis. Differences were considered significant at the level of 0.05 .

\section{Results}

During the study period, 14 patients experienced blood oozing from tumor and in all cases, Hemospray was used as the firstline hemostatic therapy. Four of those patients were excluded because they received either chemoembolization or radiation therapy within 72 hours after Hemospray, although there was no evidence of rebleeding. Subsequently, 10 patients were eligible for analysis.

Historical controls were selected from the medical record of patients during 2010 and 2014. Seventeen patients were found to have presented with upper gastrointestinal bleeding from tumor confirmed by endoscopy but only 10 of them were matched in terms of bleeding location and bleeding activity of blood oozing and selected as a control group (upper gastrointestinal tumor, $n=5$ and hepatico-pancreaticobiliary tumor, $n=5$ ). Baseline characteristics including age, stage of tumor and Blatchford score did not differ between the intervention and control groups ( $\bullet$ Table 1). The volume of blood transfused was higher in the Hemospray group ( $10.5 \pm 16.0$ vs. $4.9 \pm 3.8$ packs; $P=0.8$ ). The 14-day rebleeding rate in the Hemospray group was 3 times lower than the control group (10\% vs. $30 \% ; P=0.60)$. Nine out 


\begin{tabular}{|llll|}
\hline Parameters & $\begin{array}{l}\text { Hemospray group } \\
(\mathbf{N = 1 0 )}\end{array}$ & $\begin{array}{l}\text { Conventional endoscopic } \\
\text { treatment group (N=10) }\end{array}$ & $P$ value \\
\hline Age (mean \pm SD; years) & $63.4 \pm 10.4$ & $60.3 \pm 13.3$ & 0.90 \\
\hline Sex (\% male) & 90 & 70 & 0.30 \\
\hline Blatchford scores (mean \pm SD) & $8.7 \pm 2.9$ & $7.9 \pm 3.3$ & 0.66 \\
\hline Advanced stage (\%) & 70 & 30 & 0.70 \\
\hline Total blood transfusion (mean \pm SD and median; unit) & $10.5 \pm 16.0$ and 5 & $4.9 \pm 3.8$ and 4 & 0.80 \\
\hline Number of total EGD (mean \pm SD) & $1.0 \pm 0$ & $1.4 \pm 0.6$ & $\mathrm{~N} / \mathrm{A}$ \\
\hline Additional intervention performed during first 10-day (\%) & 0 & 30 & $\mathrm{~N} / \mathrm{A}$ \\
\hline Additional intervention performed during admission (\%) & 10 & 70 & 0.30 \\
\hline 14-day rebleeding rate (\%) & 10 & 30 & 0.60 \\
\hline Length of hospital stay (mean \pm SD; day) & $28.2 \pm 21.2$ & $23.8 \pm 12.5$ & 0.26 \\
\hline 30-day mortality rate (\%) & 10 & 30 & 0.70 \\
\hline
\end{tabular}

Table 1 Baseline characteristics and results of treatment with $\mathrm{He}$ mospray and with conventional endoscopic treatment.

Table 2 Detailed course of patients in the Hemospray group.

\begin{tabular}{|c|c|c|c|c|c|c|c|c|c|c|c|}
\hline Case & Sex & Age & Cancer & $\begin{array}{l}\text { Advance } \\
\text { stage }\end{array}$ & $\begin{array}{l}\text { Blatchford } \\
\text { Score }\end{array}$ & $\begin{array}{l}\text { Total } \\
\text { PRC }\end{array}$ & $\begin{array}{l}\text { Rescue } \\
\text { treatment }\end{array}$ & $\begin{array}{l}\text { 14-day } \\
\text { rebleed }\end{array}$ & $\begin{array}{l}\text { 30-day } \\
\text { rebleed }\end{array}$ & $\begin{array}{l}\text { Death } \\
\text { (day after spray) }\end{array}$ & $\begin{array}{l}\text { LOS } \\
\text { (days) }\end{array}$ \\
\hline 1 & $M$ & 74 & CCA & Yes & 11 & 7 & No & No & No & No & 40 \\
\hline 2 & $\mathrm{~F}$ & 55 & CCA & Yes & 7 & 1 & No & No & Yes, d 20 & Yes, d 20 & 10 \\
\hline 3 & M & 80 & $\mathrm{HCC}$ & Yes & 11 & 4 & No & No & No & Yes, d 50 & 50 \\
\hline 4 & M & 56 & CA stomach & No & 2 & 4 & No & No & No & No & 15 \\
\hline 5 & M & 69 & $\begin{array}{l}\text { Metastatic } \\
\text { to stomach }\end{array}$ & Yes & 11 & 9 & No & No & No & No & 4 \\
\hline 6 & M & 46 & CA stomach & Yes & 7 & 6 & No & No & No & No & 38 \\
\hline 7 & $M$ & 63 & $\mathrm{HCC}$ & No & 11 & 4 & No & No & No & No & 15 \\
\hline 8 & M & 72 & CA stomach & Yes & 7 & 55 & No & Yes, no EGD & Yes, no EGD & Yes, d 70 & 70 \\
\hline 9 & M & 56 & CA stomach & No & 9 & 13 & Yes, Surgery d 12 & No & No & No & 30 \\
\hline 10 & M & 63 & $\mathrm{HCC}$ & Yes & 11 & 2 & No & No & No & No & 10 \\
\hline
\end{tabular}

CA, carcinoma; CCA, cholangiocarcinoma; HCC: hepatocellular carcinoma; PRC, packed red cells; LOS, length of hospital stay; N/A, no data available

of 10 patients in the Hemospray group did not undergo additional intervention during the first 14 days. Although there was no rebleeding, on Day 12, 1 patient with bleeding gastric cancer who had previously been scheduled for elective surgery underwent a partial gastrectomy ( $\bullet$ Table 2 ). Three of 10 patients $(30 \%)$ in the control group re-bled and required a rescue intervention during the first 14 days and another 4 patients $(40 \%)$ underwent additional intervention according to a prescheduled plan ( $\bullet$ Table 3 ). In all 3 patients, rebleeding occurred quite early (within 48 hours) ( $\bullet$ Table 3). LOS did not differ between the 2 groups ( $28.2 \pm 21.2$ days vs. $23.8 \pm 12.5$ days; $P=0.26$ ). The 30 -day mortality rate in the Hemospray group was 3 times lower than in the conventional therapy group (10\% vs. $30 \%, P=0.7$ ) ( $\odot$ Table 1$)$. Moreover, no adverse effects were reported during the follow-up period.

\section{Discussion}

$\nabla$

Because most incidents of active tumor bleeding are difficult to control with conventional endoscopic hemostatic techniques such as coaptation, hemoclipping, and band ligation, $[1,4,5]$ there is a need for bridging therapy. Hemospray is well suited for treatment of upper gastrointestinal bleeding from tumor because it provides temporary hemostasis while allowing time to schedule a patient for more definitive treatment such as surgery, angiographic embolization, or radiation. The mechanism of tumor bleeding is explained by erosion of the raw surface of a malignant lesion. In addition, acidic content from the stomach can promote more bleeding because it dissolves clot and possibly digests tumor tissue that lacks a barrier of mucous and epithe- lium [4]. Although conventional endoscopic hemostatic techniques can provide immediate control for some tumor bleeding, it tends to recur in a short period of time $[1,4,5]$. It is possible that the conventional endoscopic treatments may fail to protect tumor tissue from digestion. In addition, if coaptation is selected, tumor necrosis may progress because of the effect of heat [12]. In contrast, Hemospray treatment can prevent tumor bleeding by providing immediate hemostasis and the powder that remains on the surface for a period of time may protect the tumor tissue from further erosion by gastric acid.

In recent years, multiple studies have been conducted to prove the efficacy of Hemospray for many different types of gastrointestinal bleeding $[9,10,13-15]$ but only 1 study focused on tumor-related gastrointestinal bleeding is available [10]. In 2012, Chen et al. reported a case series of upper gastrointestinal bleeding from different types of tumors which was successfully controlled by Hemospray [10]. In their series, there were 3 gastric cancers, 1 pancreatic cancer invading duodenum, and 1 metastatic breast cancer invading duodenum. Four of 5 patients $(80 \%)$ subsequently received chemotherapy or radiotherapy within 5 days after initial hemostasis with Hemospray although there was no evidence of rebleeding during the 5-day observation [10]. Based on experience in a very limited number of patients, the authors concluded that Hemospray may be useful for both immediate hemostasis and as a bridging treatment for further adjuvant therapy.

To our knowledge, this is the first study that compares the hemostatic effect of Hemospray with conventional treatment for upper gastrointestinal bleeding from tumor. To demonstrate the longer hemostatic effect of Hemospray in bleeding tumor, the current 
Table 3 Detailed course of patients in the control group.

\begin{tabular}{|c|c|c|c|c|c|c|c|c|c|c|c|c|}
\hline Control & Sex & Age & Cancer & $\begin{array}{l}\text { Advance } \\
\text { stage }\end{array}$ & $\begin{array}{l}\text { Blatchford } \\
\text { score }\end{array}$ & $\begin{array}{l}\text { Total } \\
\text { PRC }\end{array}$ & Endoscopic Rx & $\begin{array}{l}\text { Rescue } \\
\text { treatment }\end{array}$ & $\begin{array}{l}\text { 14-day } \\
\text { rebleed }\end{array}$ & $\begin{array}{l}\text { 30-day } \\
\text { rebleed }\end{array}$ & $\begin{array}{l}\text { Death } \\
\text { (day after } \\
\text { admission) }\end{array}$ & LOS \\
\hline 1 & $\mathrm{~F}$ & 43 & $\mathrm{HCC}$ & Yes & 5 & 5 & No & $\begin{array}{l}\text { Yes, TACE } \\
\text { at } d 1\end{array}$ & Yes, d 1 & $\mathrm{~N} / \mathrm{A}$ & Yes, d 9 & 9 \\
\hline 2 & $\mathrm{~F}$ & 57 & CA HOP & No & 10 & 3 & $\begin{array}{l}\text { Yes, Adrenaline } \\
\text { injection }\end{array}$ & $\begin{array}{l}\text { Yes, Surgery } \\
\text { at } d 40\end{array}$ & No & No & Yes, d 50 & 50 \\
\hline 3 & $\mathrm{~F}$ & 79 & CA GB & No & 8 & 4 & Yes, APC & No & N/A & $\mathrm{N} / \mathrm{A}$ & No & 10 \\
\hline 4 & M & 57 & $\begin{array}{l}\text { CA } \\
\text { stomach }\end{array}$ & No & 4 & 4 & No & $\begin{array}{l}\text { Yes, Surgery } \\
\text { at } d 20\end{array}$ & No & No & No & 30 \\
\hline 5 & M & 67 & $\begin{array}{l}\text { CA } \\
\text { stomach }\end{array}$ & No & 2 & 1 & No & $\begin{array}{l}\text { Yes, Surgery } \\
\text { at } d 15\end{array}$ & No & No & No & 28 \\
\hline 6 & M & 45 & $\begin{array}{l}\text { CA } \\
\text { stomach }\end{array}$ & Yes & 9 & 15 & No & No & Yes, d2, APC & $\mathrm{N} / \mathrm{A}$ & Yes, d 16 & 16 \\
\hline 7 & M & 65 & $\begin{array}{l}\text { CA } \\
\text { ampulla }\end{array}$ & Yes & 7 & 5 & No & $\begin{array}{l}\text { Yes, RT } \\
\text { at d } 2\end{array}$ & Yes, d2, RT & No & No & 21 \\
\hline 8 & M & 83 & $\begin{array}{l}\text { CA } \\
\text { stomach }\end{array}$ & No & 12 & 6 & No & No & No & No & No & 24 \\
\hline 9 & M & 50 & $\begin{array}{l}\text { CA } \\
\text { esophagus }\end{array}$ & No & 11 & 4 & No & No & No & No & No & 15 \\
\hline 10 & M & 57 & CA HOP & No & 11 & 2 & No & $\begin{array}{l}\text { Yes, Surgery } \\
\text { at } d 6\end{array}$ & No & No & No & 36 \\
\hline
\end{tabular}

CA, carcinoma; HCC, hepatocellular carcinoma; HOP, head of pancreas; GB, gallbladder; PRC, Packed red blood cells; APC, argon plasma coagulation; TACE, transarterial chemoembolization; RT, radiation therapy; LOS, length of hospital stay; d, day; N/A, no data available

study excluded patients who received definitive treatment within 72 hours. We could not, however, demonstrate statistical significance given the limited number of cohorts but we did demonstrate a trend toward lower rates of recurrent bleeding in 14 days ( $10 \%$ vs. $30 \%, P=0.6$ ) and a lower mortality rate at 30 days ( $10 \%$ vs. $30 \%, P=0.7)$. In addition, no additional treatment was needed after Hemospray application in all except 1 patient during hospitalization whereas $30 \%$ of patients in the control group required additional treatment.

The limitation of the present study is a rather small number of cases, which made it impossible to make a pair match in other parameters apart from the location of tumor. In addition, we believe that more patients would have allowed the results to rise to statistical significance, as we showed a large gap in outcomes between the 2 groups. Furthermore, no patients had bleeding from a lower gastrointestinal tract tumor. Because little acid is involved in rebleeding from such tumors, the efficacy of Hemospray in those patients needs to be demonstrated and its differing mechanism of action in that setting explained.

\section{Conclusions}

Hemospray is a promising therapy for initial hemostasis in upper gastrointestinal bleeding from tumor because it can achieve hemostasis during the first 14 days, which may allow sufficient time before consideration of appropriate additional intervention.

\section{Competing interests: None}

\section{References}

1 Heller SJ, Tokar JL, Nguyen MT et al. Management of bleeding gastrointestinal tumors. Gastrointest Endosc 2010; 72: 817-824

2 Padmanabhan A, Douglass HO Jr, Nava HR. Role of endoscopy in upper gastrointestinal bleeding in patients with malignancy. Endoscopy 1980; $12: 101-104$
3 Lightdale CJ, Kurtz RC, Sherlock P et al. Aggressive endoscopy in critically ill patients with upper gastrointestinal bleeding and cancer. Gastrointest Endosc 1974; 20: 152 - 153

4 Adler DG, Leighton JA, Davila RE et al. ASGE guideline: The role of endoscopy in acute non-variceal upper-gastrointestinal hemorrhage. Gastrointest Endosc 2004; 60: 497-504

5 Asge Technology Committee. Conway JD, Adler DG et al. Endoscopic hemostatic devices. Gastrointest Endosc 2009; 69: 987-996

6 Poultsides GA, Kim CJ, Orlando R et al. Angiographic embolization for gastroduodenal hemorrhage: safety, efficacy, and predictors of outcome. Arch Surg 2008; 143: 457 - 461

7 Lee HJ, Shin JH, Yoon HK et al. Transcatheter arterial embolization in gastric cancer patients with acute bleeding. Eur Radiol 2009; 19: 960-965

8 Asakura $H$, Hashimoto T, Harada $H$ et al. Palliative radiotherapy for bleeding from advanced gastric cancer: is a schedule of $30 \mathrm{~Gy}$ in 10 fractions adequate? J Cancer Res Clin Oncol 2011; 137: 125-130

9 Sung JJ, Luo $D, W u J C$ et al. Early clinical experience of the safety and effectiveness of Hemospray in achieving hemostasis in patients with acute peptic ulcer bleeding. Endoscopy 2011; 43: 291 - 295

10 Chen YI, Barkun AN, Soulellis C et al. Use of the endoscopically applied hemostatic powder TC-325 in cancer-related upper gastrointestinal hemorrhage: preliminary experience (with video). Gastrointest Endosc 2012; 75: 1278 - 1281

11 Holster IL, Kuipers EJ, Tjwa ET. Hemospray in the treatment of upper gastrointestinal hemorrhage in patients on antithrombotic therapy. Endoscopy 2013; 45: 63-66

12 Tjwa ET, Holster IL, Kuipers EJ. Endoscopic management of nonvariceal, nonulcer upper gastrointestinal bleeding. Gastroenterology clinics of North America 2014; 43: 707 - 719

13 Chen YI, Barkun A, Nolan S. Hemostatic powder TC-325 in the management of upper and lower gastrointestinal bleeding: a two-year experience at a single institution. Endoscopy 2015; 47: 167-171

14 Smith LA, Stanley AJ, Bergman JJ et al. Hemospray application in nonvariceal upper gastrointestinal bleeding: results of the Survey to Evaluate the Application of Hemospray in the Luminal Tract. J Clin Gastroenterol 2014; 48: e89-92

15 Sulz MC, Frei R, Meyenberger C et al. Routine use of Hemospray for gastrointestinal bleeding: prospective two-center experience in Switzerland. Endoscopy 2014; 46: 619-624

16 Laine L, Jensen DM. Management of patients with ulcer bleeding. Am J Gastroenterol 2012; 107: 345 - 360; quiz 361 